Seção Temática: Balanço do Fundeb

Volume 10 - $2020 \mid$ n. 31

\title{
Resenha: Fundeb pra Valer! A incidência política da Campanha Nacional pelo Direito à Educação na criação do Fundo da Educação Básica
}

\author{
Idevaldo da Silva Bodião \\ Universidade Estadual do Ceará (UECE), Fortaleza/CE - Brasil
}

NASCIMENTO, Iracema Santos do (Org.). FUNDEB PRA VALER! A incidência política da Campanha Nacional pelo Direito à Educação na criação do Fundo da Educação Básica. São Paulo: Chiado Books, 2019. 301 p.

A obra publicada com o título Fundeb pra Valer! A incidência política da Campanha Nacional pelo Direito à Educação na criação do Fundo da Educação Básica, organizada pela professora Iracema Santos do Nascimento, é constituída por uma coletânea de artigos que tem como autores a própria organizadora, além de Paulo de Sena Martins e do professor José Marcelino de Rezende Pinto; é apresentada por Carlos Roberto Jamil Cury, professor emérito da Faculdade de Educação da UFMG, e tem prefácio, de dezembro de 2018, e posfácio, de março de 2019, assinados por Daniel Cara, à época coordenador da Campanha Nacional pelo Direito à Educação.

Embora corretamente tipificada como uma coletânea de artigos, mais justo seria classificá-la, com todo o respeito aos colaboradores, como um texto autoral da professora Iracema Santos do Nascimentos (História da incidência política da Campanha Nacional pelo Direito à Educação na criação do Fundeb, p. 59-262), complementado pelas colaborações, preciosas e cirúrgicas, do professor José Marcelino de Rezende Pinto, em artigo partilhado com a própria organizadora ( $\mathrm{O}$ sistema de financiamento da educação básica pública no Brasil, p. 25-46) e em texto solo (Pensando além do Fundeb, p. 263-280) e do consultor da Câmara dos Deputados, Paulo de Sena Martins (A Campanha Nacional pelo Direito à Educação e a aprovação do Fundeb, p. 47-57).

Na sua apresentação, transitando na evolução do Fundef para o Fundeb, o professor Jamil Cury reafirma o Estado como um lugar de disputas de vários interesses, onde o convencimento do outro se faz com argumentos, estatísticas e habilidades no manuseio das informações e cunha uma síntese que retrata a essência da originalidade do texto, ao afirmar que "a lição de fundo que este livro nos traz é de método" (p. 22, em negrito no original).

Ao longo de suas mais de 250 páginas, o livro traz o registro das ações articuladas da sociedade civil nas mobilizações em torno da aprovação do Fundeb, com primorosa riqueza de detalhes e uma gama variada de fontes de informações, que fará dele importante fonte de pesquisa para tantos quantos se ocupem em estudar as atuações dos movimentos sociais nas pautas educacionais nas primeiras décadas deste século; ao mesmo tempo, traz uma contribuição bastante original, pois, sem perder o rigor acadêmico, nos oferece um método- 
referência para mobilizações e atuações dos movimentos sociais em embates políticos semelhantes, dinâmicas, aliás, repetidas, em boa parte, durante as ações que a mesma Campanha engendrou, por exemplo, desde o início do processo conferencial até a promulgação da lei 13.005/2014, que instituiu o Plano Nacional de Educação, história, aliás, que está para ser narrada.

A primeira contribuição do professor Marcelino Pinto, aqui em parceria com a organizadora, Iracema do Nascimento, abre a coletânea em texto que pretende apresentar os caminhos do financiamento da educação básica pública no Brasil (O sistema de financiamento da educação básica pública no Brasil, p. 25-46). Para tanto, recuperam suas bases legais, remetendo-nos à Constituição Federal de 1988 e à LDBEN de 1996, tecem considerações sobre o Fundef, sem deixar de ressaltar o seu não cumprimento pela União e nos abrem as portas do Fundeb ao mostrar seu funcionamento, com importantes críticas aos fatores de ponderações, lembrando-nos, ainda que tangencialmente, suas diferenças com as conceituações e os valores do Custo Aluno-Qualidade Inicial, o CAQi ${ }^{1}$, outro foco de atuação importante de ações da Campanha².

Paulo de Sena Martins inicia seu artigo (A Campanha Nacional pelo Direito à Educação e a aprovação do Fundeb, p. 47-57) rememorando as articulações e as atuações de entidades da sociedade civil, em momentos como a tramitação e aprovação do Fundef (Emenda Constitucional 14/1996 e Lei $n^{\circ}$ 9.424/1996) e na construção do documento intitulado "Plano Nacional de Educação: Proposta da Sociedade Brasileira", aprovado no II Coned, em novembro de 1997, para, na sequência, tecer considerações sobre o surgimento da Campanha, em 1999, assinalando que na "[...] construção do Fundeb, o protagonismo das entidades representativas do movimento social foi mais significativo" (p. 50).

Martins (2019) destaca o papel da Campanha como articuladora de um conjunto de entidades educacionais, registrando suas ações nas lutas contra o não cumprimento, por parte do governo federal, de regras do Fundef, nas discussões sobre as concepções do CAQi e CAQ e as lutas pela inclusão das creches no Fundeb, que estava em discussão naquele momento, narrando os fluxos e contrafluxos próprios das casas legislativas, com destaque, neste caso, para as atuações das entidades do movimento social na forma de pressões políticas ancoradas em entendimentos técnicos.

Naquele que é a espinha dorsal do livro, o artigo/texto da professora Iracema Santos do Nascimento (História da incidência política da Campanha Nacional pelo Direito à Educação na criação do Fundeb, p. 59-262) narra, com precisão histórica e fluência jornalística, a trajetória das ações da Campanha, organizando-a, didaticamente, em três períodos: (i) de março de 2004 a junho de 2005, p. 64-88, identificando-o como a etapa de pressão no Executivo; (ii) de junho de 2005 a dezembro de 2006, p. 88-171, a etapa de mobilização social durante a criação da Emenda Constitucional do Fundeb e (iii) de dezembro de 2006 a junho de 2007, p. 171-210, período de incidência sobre a Medida Provisória. Cada período

1 CAQi, Custo Aluno-Qualidade Inicial e CAQ, Custo Aluno-Qualidade são concepções desenvolvidas pela Campanha; informações atualizadas podem ser encontradas em: <https://campanha.org.br/caqi-caq/>. Acesso em: 19 jun. 2020.

2 A partir daqui as alusões à Campanha Nacional pelo Direito à Educação se darão, de modo simplificado, identificando-a como Campanha. 
mencionado, marcado por ações específicas da Campanha, decorreu de longo e meandroso percurso que incluiu elaboração, tramitação e aprovação do Fundeb.

Na primeira etapa, estão narradas as interlocuções iniciais com o MEC do que viria a ser o Fundeb; estão aí as iniciativas do então Ministro da Educação, Tarso Genro, os primeiros conflitos com o Ministério da Fazenda, as participações do movimento social nos colóquios e conferências e a constatação da primeira grande frustração: a não inclusão das creches na proposta do fundo a ser encaminhada pelo governo. A narração desses movimentos é recheada de referências às suas repercussões na mídia nacional, bem como de depoimentos de atores importantes nesse processo.

A segunda etapa inicia-se, pode-se dizer, no mesmo dia em que o governo federal apresenta ao Congresso Nacional a Proposta de Emenda Constitucional n $n^{\circ}$ 415/2005 e tem no movimento "Fundeb pra Valer!" o ponto central de articulação das ações da sociedade civil. Preservando o rigor da narrativa, aqui são descritas as ações do movimento "Fundeb pra Valer!" durante as tramitações nas casas legislativas, as proposições de emendas, as participações nas audiências, as conquistas na Câmara dos Deputados, as resistências no Senado Federal, as pressões do Executivo, a morosidade de um processo que tinha urgência e que culminou com a aprovação, em sessão conjunta da Câmara dos Deputados e do Senado Federal, da Emenda Constitucional n 53, em 19 de dezembro de 2006, "aos 45 minutos do segundo tempo", para usar uma linguagem futebolística, afinal, a Emenda Constitucional $n^{\circ}$ 14/1996, que aprovou o que viria a ser o Fundef, tinha vigência até 2006!

A terceira etapa narrada recupera as ações da incidência social no período de tramitação da regulamentação da EC 53/2006, que, por conta da necessidade urgentíssima de aprovação, precisou se dar na forma de Medida Provisória, a de número 339, de 28 de dezembro de 2006! O prazo curto desse processo, embora tenha dificultado as ações do movimento "Fundeb pra Valer!", não impediu a repetição de estratégias utilizadas em outras etapas, tais como as negociações com o Executivo, as produções de documentos, as elaborações de emendas e as participações em audiências e atos públicos, como aquele realizado em 7 de março de 2007, conhecido como "Fraldas pintadas", que reuniu cerca de 200 pessoas, "[...] incluindo mães, crianças, estudantes, parlamentares, ativistas de organizações e movimentos das áreas educacional, empresarial, feminista, entre outros [que] coloriu o gramado em frente à rampa do Congresso Nacional" (p. 189-190)

Correndo contra o tempo, o que é próprio das medidas provisórias, e contra resistências nas duas casas legislativas, as reivindicações do movimento "Fundeb pra Valer!" tiveram enormes dificuldades para prosperar, de modo que o Fundeb, sancionado pelo presidente Luiz Inácio Lula da Silva, lei n 11.494/2007, ficou muito aquém das necessidades das escolas públicas brasileiras, ainda que, é preciso reconhecer, teria sido um documento bastante pior se não fossem as ações contínuas e vigilantes dos movimentos sociais, particularmente aqueles organizados em torno do movimento "Fundeb pra Valer!".

Nas páginas seguintes, a autora discorre sobre as estratégias utilizadas pelo movimento ao longo de cada uma das etapas anteriormente assinaladas, descrevendo-as em detalhes; são elas: as articulações de distintos atores dos movimentos sociais, as pressões políticas sobre os parlamentares das casas legislativas, as ações de mobilização social, reservando, aqui, espaços para descrições de inúmeros eventos realizados em vários estados brasileiros, as estratégias de comunicação, a produção de conhecimento e a formação de atores sociais. 
Resenha: Fundeb pra Valer!

Tais descrições são complementadas, no item seguinte, por um conjunto de reflexões, importantíssimas, sobre os aprendizados da sociedade civil, ao tempo de cada uma dessas ações; destacam-se: o caráter do movimento e as condições de sua composição, as delicadas ações necessárias para manter um grupo heterogêneo fortemente mobilizado e unido em torno de um propósito, as formas de relações com o executivo e com as casas legislativas, sem deixar que se convertam em cooptações, as relações com a mídia, entendida como importante instrumento de formação de opiniões e de pressão sobre as autoridades, e, por fim, as estratégias de formação dos atores sociais envolvidos.

O último artigo deste livro traz nova contribuição do professor José Marcelino de Rezende Pinto (Pensando além do Fundeb, p. 263-280), no qual, reconhecendo as limitações da formulação atual do Fundeb, as restrições financeiras impostas pela Emenda Constitucional 95/2016, o caráter temporário da atual formulação do fundo e considerando as discussões da PEC 15/2015, na Câmara dos Deputados, se pergunta se, para resolver os desafios da educação brasileira, bastaria perenizar o Fundeb.

Respondendo negativamente à própria pergunta, ele faz questão de ressaltar, no entanto, que o Fundeb foi responsável pela diminuição das desigualdades dos valores anuais por aluno praticados pelos estados brasileiros, ao mesmo tempo que apresenta substantiva quantidade de dados que sustentam sua argumentação, segundo a qual os valores mínimos do Fundeb, ainda que com os atuais fatores de ponderações, estão muito abaixo das necessidades da nossa escola pública, e o faz confrontando-os com os valores obtidos a partir daqueles oriundos da aplicação do Custo Aluno-Qualidade Inicial ${ }^{3}$, nos vários níveis, modalidades, localizações e durações das jornadas diárias de atividades.

Ao finalizar o artigo, tece considerações sobre o peso específico das receitas do Imposto sobre Circulação de Mercadorias e Serviços (ICMS) e sua sensível vinculação com os ciclos da economia, traço que se tornou mais importante neste período de enorme retração econômica em decorrência da pandemia do Covid 19, e o conclui listando os pontos importantes a serem considerados no futuro Fundeb: a necessidade de sua perenização e o reconhecimento dos seus limites para a expansão da escolarização, o que ensejaria uma ampliação no papel da União como ente equalizador do fundo, algo que pode ser conseguido com a adoção do CAQi e CAQ como fatores de definição dos recursos por aluno do novo fundo para as diferentes etapas de modalidades, com a União responsabilizando-se por, pelo menos, metade dos seus recursos para se garantir o CAQi nos termos propostos pela Campanha.

O livro é uma obra que possui vários méritos, cujo valor central está no registro histórico, preciso e detalhado dos movimentos engendrados no xadrez político praticado durante a construção da lei que regulamenta o Fundo de Manutenção e Desenvolvimento da Educação Básica e de Valorização dos Profissionais da Educação (FUNDEB) (Lei n 11.494/2007).

É preciso reconhecer que havia, à época de sua implementação, condições para estabelecimentos de diálogos, tanto com setores do executivo federal, quanto com o congresso nacional, impensáveis nos dias de hoje; é necessário reconhecer, também, que a Campanha soube aproveitá-las, o que, como já se disse, está fartamente documentado neste

3 Ele faz referência ao Parecer CNE/CEB n 8/2010, que, à época em que o artigo foi escrito, ainda não havia sido "derrubado" pelo Parecer CNE/CEB n 3/2019. 
Resenha: Fundeb pra Valer!

livro. Compreender todos esses movimentos, suas origens e decorrências, neste momento de fortalecimento de ofensivas autoritárias, marcadas pela improvável conjunção de uma concepção neoliberal na economia, com um conservadorismo nos costumes, pode ser fator importante para que os movimentos sociais ajustem, ainda uma vez mais, suas ações nas lutas pela defesa da educação como um direito, portanto de todos, e que os pesquisadores igualmente ajustem algumas das variáveis que orientam seus projetos de pesquisas, o que faz com que este seja um livro essencial tanto para os estudiosos, quanto para os militantes da educação pública, gratuita, laica, democrática e socialmente referendada. Boa leitura!

Idevaldo da Silva Bodião é professor aposentado, do Departamento de Teoria e Prática do Ensino da Faculdade de Educação da Universidade Federal do Ceará (UFC), professor do Centro de Educação da UECE; doutoramento em Didática, pela FEUSP e pós-doutoramento em Políticas Educacionais, na Universidade do Minho (Braga, Portugal).

ORCID: http://orcid.org/0000-0001-5371-5139

E-mail: idbodiao@uol.com.br 


\section{Editores do volume 10}

Márcia Aparecida Jacomini - Universidade Federal de São Paulo, Brasil

José Marcelino de Rezende Pinto - Universidade de São Paulo, Brasil

\section{Comitê Editorial}

Nalú Farenzena - Universidade Federal do Rio Grande do Sul, Brasil

Juca Gil - Universidade Federal do Rio Grande do Sul, Brasil

Theresa Adrião - Universidade Estadual de Campinas, Brasil

Ângelo Ricardo de Souza - Universidade Federal do Paraná, Brasil

\section{Conselho Editorial}

\section{Alejandro Morduchowicz}

Universidad Pedagógica, Provincia de Buenos Aires, Argentina

Andréa Barbosa Gouveia

Universidade Federal do Paraná, Brasil

Fernanda Saforcada

Universidade de Buenos Aires, Argentina

Jacques Velloso

Universidade de Brasília, Brasil

João Monlevade

Senado Federal, Brasil

Jorge Abrahão de Castro

Instituto de Pesquisa Econômica Aplicada / IPEA, Brasil

Lisete Regina Gomes Arelaro

Universidade de São Paulo, Brasil

Luis Carlos Sales

Universidade Federal do Piauí, Brasil

Luiz de Sousa Junior

Universidade Federal da Paraíba, Brasil

Luiz Fernandes Dourado

Universidade Federal de Goiás, Brasil

Magna França

Universidade Federal do Rio Grande do Norte, Brasil

Marcos Edgar Bassi

Universidade Federal de Santa Catarina, Brasil

Maria Angélica Pedra Minhoto

Universidade Federal de São Paulo, Brasil

Maria Beatriz Luce

Universidade Federal do Rio Grande do Sul, Brasil

Maria Dilnéia Espíndola Fernandes

Universidade Federal de Mato Grosso do Sul, Brasil

Nelson Cardoso do Amaral

Universidade Federal de Goiás, Brasil

Nicholas Davies

Universidade Federal Fluminense, Brasil

Robert E. Verhine

Universidade Federal da Bahia, Brasil

Romualdo Portela de Oliveira

Universidade de São Paulo, Brasil

Rosana Gemaque Rolim

Universidade Federal do Pará, Brasil

Rubens Barbosa de Camargo

Universidade de São Paulo, Brasil

Theresa Adrião

Universidade Estadual de Campinas, Brasil

Tristan McCowan

University of London, Reino Unido

Vera Jacob

Universidade Federal do Pará, Brasil

Vera Peroni

Universidade Federal do Rio Grande do Sul, Brasil

Vitor Henrique Paro

Universidade de São Paulo, Brasil

\section{Equipe editorial}

Apoio ao Comitê Editorial: Caio Cabral da Silva

Diagramação, Revisão de português e normalização: Edson Leonel de Oliveira

Revisão de inglês: Sabrina Ferreira

Fineduca - Revista de Financiamento da Educação

Associação Nacional de Pesquisa em

Financiamento da Educação

e-mail: revista.fineduca@gmail.com | site: http://seer.ufrgs.br/fineduca 